\title{
Effectiveness of optometrist screening for diabetic retinopathy using slit-lamp biomicroscopy
}

Abstract

Purpose To assess the effectiveness of optometrists as screeners for diabetic retinopathy using slit-lamp binocular indirect ophthalmoscopy through dilated pupils. Methods Prospective study of a screening scheme. Screening was performed by 27 locally accredited optometrists in their practice. The referral protocol used a new simple grading system of retinopathy, especially designed for use in an optometrist screening programme. All positive referrals and $10 \%$ of negative referrals were reexamined by an ophthalmologist. Sensitivity, specificity, likelihood ratios and technical failure rates were calculated.

Results The optometrists screened 4904 people with diabetes in 18 months.

'Subthreshold' (screen negative) reports accounted for 4438 (90.5\% of 4904$) ; 429$ (9.67\%) of these were re-examined at secondary screening. There was disagreement regarding grading in 13 patients, of whom $5(1.16 \%$ of 429) had sight-threatening retinopathy (STDR); this extrapolates to 52 patients if all the 4438 test-negatives had been examined. Of the 371 'threshold' patients, $112(30.18 \%)$ were false positives; the commonest cause for false positive referral was drusen in patients with background diabetic retinopathy. The sensitivity for identification of STDR was $\mathbf{7 6} \%$ $(95 \%$ CI $70 \%$ to $81 \%)$ and specificity $95 \%(95 \%$ CI $95 \%$ to $96 \%$ ). The likelihood ratio of a positive test indicating STDR was 16.54 (95\% CI 14.17 to 19.23) and that of a negative test 0.25 (95\% CI 0.20 to 0.32$)$. The technical failure rate was $0.2 \%$.

Conclusions Suitably trained and accredited community optometrists performed well when screening for diabetic retinopathy using slitlamp biomicroscopy through a dilated pupil. This was facilitated by the use of simple grading and referral criteria. The sensitivity, positive likelihood ratio and specificity were high.

Key words Diabetes mellitus, Mass screening, Optometry, Retinopathy
SOMDUTT PRASAD, GIRISH G. KAMATH, KAREN JONES, LOUIS G. CLEARKIN, RUSSELL P. PHILLIPS

Diabetic retinopathy satisfies all the cardinal criteria necessary to justify the establishment of a screening service as it has a known natural history, an asymptomatic phase when screening can identify at-risk patients, and effective treatment can be delivered and the target population can be readily identified. In spite of this, establishment and uptake of screening services have been patchy in the UK and elsewhere, ${ }^{1-3}$ with great variation in screening methods and population coverage. Because of this approximately 300 cases of preventable visual loss occur amongst people with diabetes annually in the UK. ${ }^{4}$ The UK national screening committee is considering the topic as a possible national priority. ${ }^{5}$ The present debate centres on what is the most suitable test and who is the most suitable screener. The candidate methods of screening are retinal photography, direct ophthalmoscopy and slit-lamp biomicroscopy. A recent systematic review ${ }^{6}$ and accompanying editorial $^{4}$ concluded that mydriatic retinal photography was effective, while there was little or no evidence to support direct ophthalmoscopy as a method of screening for diabetic retinopathy; adequate studies reporting the effectiveness of screening using slit-lamp biomicroscopy were not available in the literature.

The Wirral Diabetic Eye Study has examined the performance of locally accredited, community-based optometrists as screeners for diabetic retinopathy using slit-lamp biomicroscopy. In this report we present the results of the first 18 months of the screening scheme, with analysis of the results to establish the sensitivity, specificity and likelihood ratios of the screening test.

\section{Methods \\ Case acquisition}

Our district diabetes register collected demographic data of all known people with diabetes from 64 of 65 general practices in the area, all hospital sites running diabetes clinics and laboratory $\mathrm{Hb}_{\mathrm{A} 1 \mathrm{c}}$ reports. This process
S. Prasad

G.G. Kamath

L.G. Clearkin

R.P. Phillips

Department of

Ophthalmology

Arrowe Park Hospital

Upton

Wirral CH49 5PE, UK

K. Jones

The Wirral District Diabetes Register

Wirral Hospitals

Upton, Wirral CH49 5PE, UK

\section{S. Prasad}

Arrowe Park Hospital

Arrowe Park Road Upton, Wirral CH49 5PE, UK

Tel: $+44(0) 1516047193$

Fax: +44 (0)1516047152

e-mail: sprasad@rcsed.ac.uk

Presented at The Oxford Ophthalmological Congress, Oxford, 2-5 July 2000 
Table 1. Grading system used by optometrists

\begin{tabular}{|c|c|c|}
\hline Subthreshold & $\begin{array}{l}\mathrm{N}: \\
\mathrm{ST}:\end{array}$ & $\begin{array}{l}\text { Normal } \\
\text { Background retinopathy (BDR) } \\
\text { BDR without features A, B, C or D }\end{array}$ \\
\hline \multirow[t]{4}{*}{ Threshold: } & A: & $\begin{array}{l}\text { BDR with maculopathy } \\
\text { Exudate or retinal thickening within } \\
\text { temporal arcades }\end{array}$ \\
\hline & B: & $\begin{array}{l}\text { Moderate/severe } B D R \\
\text { Severe retinal haemorrhage (blot) in at } \\
\text { least two quadrants, OR cotton wool spots, } \\
\text { venous beading, IRMA present in any } \\
\text { quadrant }\end{array}$ \\
\hline & & $\begin{array}{l}\text { Proliferative } \\
\text { NVD or NVE }\end{array}$ \\
\hline & & $\begin{array}{l}\text { Advanced diabetic eye disease } \\
\text { Preretinal or vitreous haemorrhage }\end{array}$ \\
\hline Comments: & $\begin{array}{l}\text { Unex } \\
\text { Othe }\end{array}$ & $\begin{array}{l}\text { xplained/uncorrectable poor visual acuity } \\
\text { r unrelated findings }\end{array}$ \\
\hline
\end{tabular}

This is accompanied by fundus photographs for guidance. NVD, new vessels on disc; NVE, new vessels elsewhere.

identified 7652 people with diabetes representing 2.12\% of the target population of 36 1050; the details of this process have been reported elsewhere. ${ }^{7}$ All people with diabetes who were not already under the care of the hospital eye service were invited to have a free eyescreening test by an accredited optometrist at a convenient optometry practice.

\section{Training and accreditation of optometrists}

All optometrists in the area were invited to participate. Respondents attended an initial lecture, following which they attended hospital eye clinics with an ophthalmologist (S.P., L.G.C. or R.P.P.). Here, they received individual 'hands-on' training in fundus examination using a 90 and $78 \mathrm{D}$ lens and gained experience in the examination and grading of fundi with diabetic retinopathy. Once the individual felt competent with these skills, they undertook an assessment. This consisted of correctly grading 12 consecutive patients with diabetic retinopathy according to the grading system used for primary screening (Table 1). Four optometrists failed to attend enough clinical sessions to complete the assessment and were therefore not accredited. Twenty-seven optometrists achieved the required standard and were accredited to screen for diabetic retinopathy.

\section{Screening process}

Screening was performed by the optometrists in their own practice. Examination consisted of a standard eye test including measurement of visual acuity and refraction, together with a dilated biomicroscopic fundus examination for assessment of diabetic retinopathy status. It was mandatory to dilate pupils and to use slitlamp biomicroscopy for fundus examination. A new simple grading system was used by the optometrists (Table 1). It was thought to be essential that the grading system used was clear but concise, so that it could be learnt and reproduced easily. Because of this, established grading systems like those used in research studies ${ }^{8-10}$ and in photographic screening systems ${ }^{11,12}$ were considered to be unsuitable for use in our programme and a new system was devised. All patients who had a 'threshold' or ungradable result at screening and $10 \%$ of those who had a 'subthreshold' result were re-examined by an ophthalmologist (S.P.). At this examination, Snellen visual acuities were recorded and fundus examination was performed through dilated pupils using $90 \mathrm{D}$ and $60 \mathrm{D}$ lenses, supplemented by Goldmann contact lens examination and binocular indirect ophthalmoscopy as needed. A more detailed grading system was used at this examination (Tables 2,3). Sightthreatening diabetic retinopathy (STDR) was defined as levels 30, 40 and 70 for retinopathy and/or levels 3 and 4 for maculopathy. For all false-positive referrals, we tried to ascertain the reason that may have led to this, on the basis of the reported findings, the drawing on the report and the findings at secondary screening. At reexamination, the examining ophthalmologist's practice was to determine the grading of retinopathy and enter this into the database before seeing the optometrist's report.

Table 2. Levels of retinopathy in the Wirral Diabetes Eye Study used at re-examination by ophthalmologist

\begin{tabular}{lll}
\hline Level & Severity & Definition \\
\hline 10 & No retinopathy & No retinopathy \\
20 & Background retinopathy (NPDR) & $\begin{array}{l}\text { Mild background change, not satisfying criteria for 'moderate' or } \\
\text { 'severe' retinopathy } \\
\text { Any one of: }\end{array}$ \\
30 & Moderate NPDR & - Four quadrants of haemorrhage (blot) \\
& - Two quadrants of venous beading \\
& - IRMA \\
40 & Severe NPDR & Any two of the three criteria for 'moderate' NPDR' \\
60 & PDR stabilised & Inactive fibrous proliferations \pm photocoagulation scars \\
70 & PDR & Active proliferative retinopathy \pm photocoagulation scars \\
90 & Ungradable & Due to media opacity
\end{tabular}

Grading done according to biomicroscopic appearance.

Ensure area up to equator has been assessed. 
Table 3. Levels of maculopathy in the Wirral Diabetes Eye Study used at re-examination by ophthalmologist

\begin{tabular}{ll}
\hline Level & Definition \\
\hline 0 & No macular oedema \\
1 & Questionable \\
2 & Macular oedema but not clinically significant \\
3 & Circinate ring but not clinically significant macular \\
& oedema \\
4 & Clinically significant macular oedema \\
5 & Macular oedema lasered previously, now stable \\
6 & Non-diabetic maculopathy \\
90 & Ungradable \\
\hline
\end{tabular}

Grading done according to biomicroscopic appearance.

Clinically significant macular oedema:

1. Thickening of retina $<500 \mu \mathrm{m}$ from centre of macula.

2. Hard exudate with thickening of adjacent retina $<500 \mu \mathrm{m}$ from centre of macula.

3. A zone of retinal thickening, $>1$ disc area located $<1$ disc diameter from centre of macula.

Disc assumed to be $1500 \mu \mathrm{m}$ diameter; $500 \mu \mathrm{m}=1 / 3$ disc diameter.

\section{Data collection and analysis}

Data from all the optometrist reports, and details of reexamination by the ophthalmologist, were entered into a custom-designed database. Statistical analysis was performed using StatsDirect version 1.6 software and the tools available at The Centre for Evidence Based Medicine website (Oxford, UK).

\section{Results}

Fig. 1 summarises the results obtained during the 18 month study period. Of the 4904 people with diabetes screened during this period, $52.8 \%$ were male and $47.2 \%$ were female. There were 32 people with diabetes aged under 16 years, 2268 in the 16-64 year age group and
Table 4. Reasons for false positive referrals $(\mathrm{n}=112)$

\begin{tabular}{lc}
\hline Reason for false positive referral & Number \\
\hline Drusen/macular degeneration: & 45 \\
$\quad$ without diabetic retinopathy = 16 & \\
with BDR only = 29 & 4 \\
Maculopathy treated by photocoagulation in the past & 6 \\
Vein occlusion & 3 \\
High myope with BDR only & 4 \\
Macular oedema queried by screener & 3 \\
Poor view due to cataract & 47 \\
No reason found & 112 \\
\hline
\end{tabular}

BDR, background diabetic retinopathy.

2604 aged over 64 years. We report test positives and negatives according to our grading system and also the number of patients with STDR in the appropriate groups. The reasons for false-positive referrals are summarised in Table 4.

As we had only examined a sample (9.6\%) of the people with diabetes reported as test-negative by the screening test, we extrapolated these results to the total population of people with diabetes who screened negative. Thus 134 people with diabetes would have satisfied the criteria for a positive test although they tested negative and, more importantly, 52 people with diabetes would have had STDR even though they were test-negative.

The screening test that we used had a sensitivity of $66 \%(95 \%$ CI $65 \%$ to $67 \%)$ and a specificity of $97 \%(95 \%$ CI $97 \%$ to $98 \%$ ), when applying the grading and referral criteria described in Table 1. The likelihood ratio of a positive test was 25.98 (95\% CI 21.36 to 31.60 ) and that of a negative test was 0.35 ( $95 \%$ CI 0.30 to 0.40$)$. For detection of STDR, the sensitivity of the test was $76 \%$ (95\% CI $70 \%$ to $81 \%$ ) and specificity $95 \%$ (95\% CI 95\% to

7652 diabetics on register

\section{Months}

\section{2 retinopathy status known}

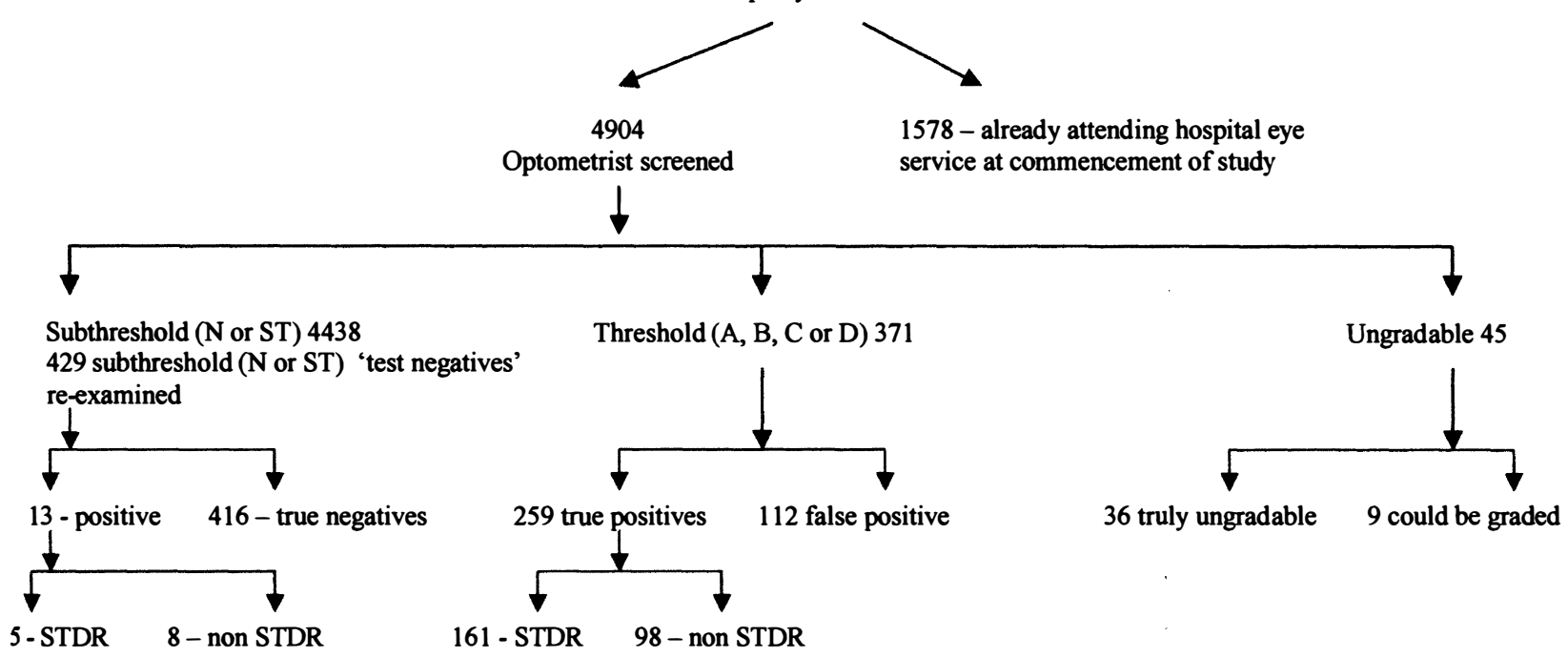

Fig. 1. Results of screening. 
$96 \%)$. The likelihood ratio of a positive test was 16.54 (95\% CI 14.17 to 19.23 ) and that of a negative test 0.26 ( $95 \%$ CI 0.20 to 0.32 ). The technical failure rate was very small: only 9 patients who should have been graded were reported as ungradable, representing $0.2 \%$ of all patients screened.

\section{Discussion}

Our screening scheme caters for all the people with diabetes in our area, the main exclusion being patients who are already under the care of the hospital eye service. The prevalence of known diabetes in our area was $2.12 \%(21.2 / 1000)$; this is comparable with recent reports from other regions. ${ }^{13-17}$ Hands-on training was provided and stringent accreditation criteria applied before optometrists were accredited to perform the screening. While no optometrist formally failed the assessment for accreditation, it is notable that four 'dropped out' during the assessment procedure and hence were not accredited.

The use of a new grading system for use by the optometrists in the screening scheme introduces difficulties when trying to compare our results with those reported by other authors. However, we thought that this was essential. The complexity of the grading systems used in research studies such as the ETDRS, ${ }^{18}$ WESDR $^{9}$ and EURODIAB ${ }^{10}$ rules them out as candidates for use in a mass screening system. The grading systems for diabetic retinopathy that are in use in photographic screening systems, as exemplified by the Welsh

Community Diabetic Retinopathy Study ${ }^{11}$ and The Liverpool Diabetic Eye Study, ${ }^{12}$ are designed for use by expert readers in a centralised facility where all photographs are read. The use of slit-lamp biomicroscopy by a large number of screeners confers some advantages and limitations compared with a photographic system, which need to be considered when choosing a grading system for use in this setting. Slitlamp biomicroscopy provides a binocular view allowing retinal thickening to be identified. Photographic systems cannot identify retinal thickening and hence use other features such as the presence of hard exudates and haemorrhages within a disc diameter of the fovea as surrogate measures to identify macular oedema; these features form an essential part of the grading systems used for photographic screening but are less important when slit-lamp biomicroscopy is used. Secondly, it is easy to count lesions and measure distances on photographs. However, when multiple fields are being examined on the slit-lamp by moving the eye it is more difficult to count lesions accurately, as individual lesions can easily be counted twice due to the dynamic nature of the examination. Also, it is easier to relate lesions to landmarks such as the vascular arcades than to measure distances when examining the fundus using the slitlamp. Finally, the use of a large number of screeners in an optometrist screening system means that the system has to be easy to memorise and reproduce in order for it to be robust when used in the community. Taking these features into consideration we devised a new grading system for use in optometrist screening programmes. This system is easy to use, reproduce and memorise, with the emphasis being placed on 'the decision to refer'. It also permits essential information about the patient to be made available to the physician (diabetologist or general practitioner) who essentially needs to know if the patient has no retinopathy, background retinopathy not requiring treatment or more advanced retinopathy needing assessment by an ophthalmologist or treatment. Subdivisions of the grade needing referral to an ophthalmologist were made to enable assessment of the urgency of referral.

The screening test as used in our setting performed well with a sensitivity of $66 \%$, a specificity of $97 \%$ and a very low technical failure rate $(9 / 4904,0.2 \%)$. We are therefore confident that our simple grading system is effective and should be easily implementable in other optometrist screening schemes. The aim of screening is to identify cases of STDR. For this, our screening system had a sensitivity of $76 \%$ with a specificity of $95 \%$. We believe that there are a variety of reasons for the moderate sensitivity. This was a learning experience for all the optometrists involved, and the emphasis was clearly placed on not missing any STDR. The relatively high false positive rate suggests that the optometrists were being relatively cautious. As experience and confidence amongst the participating optometrists grow, we hope that the false positive rate will reduce. The main cause of false positive grading was drusen that were wrongly thought to be exudates. With increasing experience and regular feedback, the participating optometrists should be able to identify such findings correctly in the future.

Formal studies of the reproducibility of the new grading system have not been undertaken and this is a limitation of our study; however, the high rate of agreement between the optometrists' reported grade and the grade assigned by the ophthalmologist at reexamination would indicate that the screeners were applying the grading criteria consistently. We did not formally mask the re-examining ophthalmologist to the screening report, but the practice was to see the screening report only after the ophthalmologist's grade had been assigned and entered into the database. This may represent a source of review-bias in our study.

A number of optometrist-based screening schemes for diabetic retinopathy are in operation across the country. ${ }^{18-27}$ Not all have included specific training, standardised grading systems or clearly defined referral protocols. Minimal research about the effectiveness of these schemes has been undertaken; the number of subjects being re-examined by the 'gold standard' is mostly of the order of 100 only. Method of examination and mydriasis have often been left to the discretion of the screener. The target population in most of these schemes is ill defined and mainly consists of people with diabetes who are under the care of the general practitioner only. This means that 'high-risk' groups are either not examined at all or have examination using direct 
ophthalmoscopy by the examining physician, a method which is well known to miss a significant proportion of STDR. ${ }^{17,28}$ Our study addresses these issues and shows that an optometrist screening scheme using slit-lamp biomicroscopy is effective.

It is interesting that most reported screening schemes for diabetic retinopathy have a moderate sensitivity and a high specificity. A recent review of diabetic retinopathy screening schemes in the UK included nine studies and separately reported results from 33 subgroups from these studies. ${ }^{29}$ Only six of these subgroups reported

sensitivity of $90 \%$ or higher but 24 reported a specificity of $90 \%$ or higher. The emphasis on specificity at the cost of sensitivity can be ascribed to a variety of reasons. The focus of screening programmes has traditionally been to avoid false positive referrals as they cause enormous anxiety to the subject and also lead to inappropriately expensive tests to confirm or disprove the findings. Whilst this is true in the setting of screening programmes such as those used for malignancies or congenital defects, where the emotional effect of having a positive screening test can be devastating and the further tests needed to elucidate the condition have significant side-effects and costs, this may not be an appropriate approach for diabetic retinopathy. Most people with diabetes are reasonably informed about their disease or have access to a multitude of sources of information about the complications of diabetes. They will expect to get retinopathy at some stage and a positive screening test for diabetic retinopathy need not cause disproportionate anxiety provided the results are conveyed in a sensitive manner. Also, effective sight-preserving treatment can be offered, and is widely known to be available, thus further allaying anxiety. The cost implications of false positive referrals remain, but as the 'gold standard' test is an examination by an ophthalmologist without the need for expensive investigations in the non-sight-threatening cases, this cost is not large. It is therefore reasonable to propose that the emphasis in screening schemes for diabetic retinopathy be shifted from ensuring a high specificity to ensuring a high sensitivity, even if that implies a slightly higher false positive referral rate. If the sensitivity of screening schemes is high, it may be possible to increase the screening interval from annual to biannual, thus reducing the inconvenience to people with diabetes and the cost of screening. ${ }^{30-32}$ We suggest that future research and screening in this field be directed to achieving a high sensitivity, even if that implies a relatively lower specificity.

Retinal photography has been advocated as the method of choice for a national screening programme for diabetic retinopathy. ${ }^{4}$ This modality of screening allows examination to be carried out in a range of settings from clinics to mobile vans, making it useful for community screening using a mobile unit. ${ }^{17,33-39}$ Suitably trained readers can then assess the photographs at a central reading facility. ${ }^{40,41}$ A study from Liverpool showed fundus photography using three $45^{\circ}$ fields, $35 \mathrm{~mm}$ film and mydriasis had a sensitivity of $89 \%$ (95\% CI $80 \%$ to $98 \%$ ) and specificity of $86 \%$ (95\% CI $82 \%$ to $90 \%)$ in assessing 358 people with diabetes. However $14.4 \%$ (46 of 320) of photographs were ungradable compared with $2.2 \%$ (7 of 320) for direct ophthalmoscopy in the same group after excluding eyes that could not be graded by any method. ${ }^{12}$ Most studies have shown a relatively high technical failure rate for fundus photography, as a significant number of films may be ungradable or unobtainable. This has been reported to be between 3.7\% to $34 \% ., 36,39,42-47$ Another study assessed the reading of $35 \mathrm{~mm}$ fundus photographs by different groups and reported that general practitioners had a sensitivity and specificity of $79 \%$ and $73 \%$ respectively, compared with optometrists who achieved $88 \%$ and $68 \%$ sensitivity and specificity and diabetologists who obtained a sensitivity and specificity $73 \%$ and $93 \%$ respectively. ${ }^{11}$ Others have also reported this variability in performance of different groups of health professionals when reading fundus photographs. A study from Mexico compared the performance of retina specialists with a standardised reading centre and found an overall agreement of only $74 \%$, and concluded that there was a significant discrepancy in the concordance level observed. ${ }^{48}$ An advantage of fundus photography is that a permanent record is available and external validation is therefore easy to organise. In comparison with these results, our acceptable high sensitivity, specificity and very low technical failure rate indicate the advantages of slit-lamp biomicroscopy as a screening tool for diabetic retinopathy. External validation of the screening system is difficult to implement when using slit-lamp biomicroscopy, as a permanent record is not available; we did not have an external validation mechanism in place. However, the de facto gold standard for fundus examination is slit-lamp biomicroscopy performed by an experienced ophthalmologist, as this is the standard on which treatment decisions are made. If other groups of health care professionals, such as optometrists, can be trained to use this effectively, and a continuing audit process is in place, external validation of the scheme should not be a necessity.

Combined-modality screening has been recommended to increase the sensitivity and specificity of screening. ${ }^{49}$ This is most likely to be significant when the sensitivity of at least one of the examination methods being used is low. For single methods that are highly sensitive, the benefit of combining this with an additional screening test is likely to be less significant, whilst increasing the cost. However, if the same operator can be trained to perform both photography and ophthalmoscopy, the additional cost can be minimised and this approach can then be cost-effective. ${ }^{50}$ Combined-modality screening can approach the 'Holy Grail' of $100 \%$ sensitivity. ${ }^{51}$ However, the study that reported this was based on a small number of subjects (144 and 145 in the two phases of the study). ${ }^{20}$

The argument about the best method of screening for diabetic retinopathy will continue. Our study does not directly address that question. A trial directly comparing different forms of screening would address that question, but is unlikely to be feasible because of the large numbers 
which will have to be screened using different methods over a long period of time in order to be able to show a difference between different methods, all of which are already known to have an acceptable sensitivity and specificity. Meaningful comparison of sensitivity and specifities reported by different studies is fraught with difficulties due to many factors. These include differences in the populations included, methods of screening used, the grading system used to define a positive screen and the gold standard used in the study. The currently available evidence is insufficient to make specific recommendations on the best method of screening, and therefore this will continue to be dictated according to local circumstances. ${ }^{29}$

In summary, community optometrists with suitable training and accreditation performed well when screening for diabetic retinopathy using slit-lamp biomicroscopy through dilated pupils. This was facilitated by the use of simplified grading and referral criteria. The sensitivity and positive likelihood ratio were high, with a moderate specificity.

\section{References}

1. Bagga P, Verma D, Walton C, Masson EA, Hepburn DA. Survey of diabetic retinopathy screening services in England and Wales. Diabetic Med 1998;15:780-2.

2. Baker R, Grimshaw G, Thompson JR, Wilson A. Services for diabetic retinopathy screening in England and Wales: a survey of ophthalmologists. Practical Diabetes Int 1999;16(2):33-4.

3. Brechner RJ, Cowie CC, Howie LJ, Herman WH, Will JC, Harris MI. Ophthalmic examination among adults with diagnosed diabetes mellitus. JAMA 1993;270:1714-8.

4. Owens DR, Gibbins RL, Kohner E, Grimshaw GM, Greenwood R, Harding S. Diabetic retinopathy screening. Diabetic Med 2000;17:493-4.

5. UK National Screening Committee. Hot topics. Preservation of sight: reducing the risk of diabetic eye disease. http:/ / www.doh.gov.uk/nsc/hottopics/hottopics_ind.htm, accessed 19 September 2000.

6. Hutchison A, McIntosh A, Peters J, et al. Effectiveness of screening and monitoring tests for diabetic retinopathy. Diabetic Med 2000;17:495-506.

7. Prasad S, Jones K, Phillips RP. Creating a district diabetes register: input from primary and secondary care is necessary for success. Br J Gen Practice 2000;50:826.

8. ETDRS. Grading diabetic retinopathy from stereoscopic color fundus photographs: an extension of the modified Airlie House classification. ETDRS report no. 10. Ophthalmology 1991;98(5 Suppl):786-806.

9. Klein R, Klein BE, Magli YL, et al. An alternative method of grading diabetic retinopathy. Ophthalmology 1986;93:1183-7.

10. Aldington SJ, Kohner EM, Meuer S, Klein R, Sjolie AK. Methodology for retinal photography and assessment of diabetic retinopathy: the EURODIAB IDDM complications study. Diabetologia 1995;38:437-44.

11. Gibbins RL, Owens DR, Allen JC, Eastman L. Practical application of the European Field Guide in screening for diabetic retinopathy by using ophthalmoscopy and $35 \mathrm{~mm}$ retinal slides. Diabetologia 1998;41:59-64.

12. Harding SP, Broadbent DM, Neoh C, White MC, Vora J. Sensitivity and specificity of photography and direct ophthalmoscopy in screening for sight threatening eye disease: the Liverpool Diabetic Eye Study. BMJ 1995;311:1131-5.
13. Wells S, Benett I, Holloway G, Harlow V. Area-wide diabetes care: the Manchester experience with primary health care teams 1991-1997. Diabetic Med 1998;15(Suppl 3):S49-53.

14. Siann T, Duncan EM, Sullivan F, Matthews D, Cromie DT. Area-wide diabetes care: the Lanarkshire experience with primary health care teams 1994-1997. Diabetic Med 1998;15(Suppl 3):54-7.

15. Morris AD, Boyle DI, MacAlpine R, et al. The diabetes audit and research in Tayside Scotland (DARTS) study: electronic record linkage to create a diabetes register. DARTS/MEMO Collaboration. BMJ 1997;315:524-8.

16. Leslie PJ, McDonald S, McDonald IA. Impressive results can be obtained without record linkage. BMJ 1998;316:472.

17. Whitford DL, Roberts SH. Registers constructed from primary care databases have advantages. BMJ 1998;316:472.

18. Burns-Cox CJ, Hart JC. Screening of diabetics for retinopathy by ophthalmic opticians. BMJ 1985;290:1052-4.

19. Vinall H, Dodson PM, Gibson JM, Eames S, O'Leary MB, Terry AM. Screening for diabetic retinopathy by optometrists with ophthalmoscopy in an urban community: the community diabetic eye screening project. (Abstract of Poster 96, presented at The British Diabetic Association Annual Professional Conference.) Diabetic Med 1995;12(Suppl 1):S40.

20. Ryder RE, Close CF, Krentz AJ, et al. A 'fail-safe' screening programme for diabetic retinopathy. J R Coll Physicians Lond 1998;32:134-7.

21. Hurwitz B, Goodman C, Yudkin J. Prompting the clinical care of non-insulin dependent (type II) diabetic patients in an inner city area: one model of community care. BMJ 1993;306:624-30.

22. Burnett S, Hurwitz B, Davey C, et al. The implementation of prompted retinal screening for diabetic eye disease by accredited optometrists in an inner city district of North London: a quality of care study. Diabetic Med 1998;15(Suppl 3):S38-43.

23. Buxton MJ, Sculpher MJ, Ferguson BA, et al. Screening for treatable diabetic retinopathy: a comparison of different methods. Diabetic Med 1991;8:371-7.

24. Leese GP, Tesfaye S, Dengler-Harles M, et al. Screening for diabetic eye disease by optometrists using slit lamps. J R Coll Physicians Lond 1997;31:65-9.

25. Dorset Health Commission. Primary care development programme; extending the services provided by high street optometrists. Bournemouth and Dorchester: Dorset Health Commission, 1993/94.

26. Pointer JS, Baranyovits P, O'Malley BP. The Kettering Diabetic Monitoring Programme: twelve months experience of an optometric practice-based scheme. Ophthalmic Physiol Optics 1998;18:401-7.

27. Jowett C. Keeping an eye on care: Bandolier 1999, http:// www.jr2.ox.ac.uk/Bandolier/ImpAct/imp02/i2-4.html, accessed 19 September 2000.

28 Owens DR, Gibbins RL, Lewis PA, Wall S, Allen JC, Morton R. Screening for diabetic retinopathy by general practitioners: ophthalmoscopy or retinal photography as $35 \mathrm{~mm}$ colour transparencies? Diabetic Med 1998;15:170-5.

29. NHS Centre for Reviews and Dissemination. Complications of diabetes: screening for retinopathy, management of foot ulcers. Effective Health Care 1999;5(4):1-12.

30. Batchelder T, Barricks M. The Wisconsin Epidemiologic Study of Diabetic Retinopathy. Arch Ophthalmol 1995;113:702-3.

31. Klein R, Klein BE, Moss SE, Cruickshanks KJ. The Wisconsin Epidemiologic Study of Diabetic Retinopathy: in reply. Arch Ophthalmol 1995;113:703-4.

32. Vijan S, Hofer TP, Hayward RA. Cost-utility analysis of screening intervals for diabetic retinopathy in patients with type 2 diabetes mellitus. JAMA 2000;283:889-96.

33. Williams R, Nussey S, Humphry R, Thompson G. Assessment of non-mydriatic fundus photography in detection of diabetic retinopathy. BMJ 1986;293:1140-2. 
34. Lairson DR, Pugh JA, Kapadia AS, Lorimor RJ, Jacobson J, Velez R. Cost-effectiveness of alternative methods for diabetic retinopathy screening. Diabetes Care 1992;15:1369-77.

35. Hayes TM, Harries J. Randomised controlled trial of routine hospital clinic care versus routine general practice care for type II diabetics. BMJ 1984;289:728-30.

36. Jones D, Dolben J, Owens DR, Vora JP, Young S, Creagh FM. Non-mydriatic Polaroid photography in screening for diabetic retinopathy: evaluation in a clinical setting. BMJ 1988;296:1029-30.

37. Mohan R, Kohner EM, Aldington SJ, Nijhar I, Mohan V, Mather HM. Evaluation of a non-mydriatic camera in Indian and European diabetic patients. Br J Ophthalmol 1988;72:841-5.

38. Chantelau E, Zwecker M, Weiss H, Kluxen G, Berger M. Fundus polaroid screening for diabetic retinopathy. Is one print per patient enough? Diabetes Care 1989;12:223-6.

39. Leese GP, Newton RW, Jung RT, Haining W, Ellingford A. Screening for diabetic retinopathy in a widely spaced population using non-mydriatic fundus photography in a mobile unit. Tayside Mobile Eye Screening Unit. Diabetic Med 1992;9:459-62.

40. British Diabetic Association. Retinal photographic screening for diabetic eye disease. London: BDA, 1997.

41. Taylor R. Practical community screening for diabetic retinopathy using the mobile retinal camera: report of a 12 centre study. British Diabetic Association Mobile Retinal Screening Group. Diabetic Med 1996;13:946-52.

42. Taylor R, Lovelock L, Tunbridge WM, et al. Comparison of non-mydriatic retinal photography with ophthalmoscopy in 2159 patients: mobile retinal camera study. BMJ 1990;301:1243-7.
43. Klein R, Klein BE, Neider MW, Hubbard LD, Meuer SM, Brothers RJ. Diabetic retinopathy as detected using ophthalmoscopy, a nonmydriatic camera and a standard fundus camera. Ophthalmology 1985;92:485-91.

44. Higgs ER, Harney BA, Kelleher A, Reckless JP. Detection of diabetic retinopathy in the community using a non-mydriatic camera. Diabetic Med 1991;8:551-5.

45. Gibbins RL, Kinsella F, Young S, Saunders J, Owens DR. Screening for diabetic retinopathy in general practice using $35 \mathrm{~mm}$ colour transparency fundal photographs. Practical Diabetes 1994;11:203-6.

46. Pugh JA, Jacobson JM, Van Heuven WA, et al. Screening for diabetic retinopathy: the wide-angle retinal camera. Diabetes Care 1993;16:889-95.

47. Penman AD, Saaddine JB, Hegazy M, et al. Screening for diabetic retinopathy: the utility of nonmydriatic retinal photography in Egyptian adults. Diabetic Med 1998;15:783-7.

48. Gonzalez ME, Gonzalez C, Stern MP, Arredondo B, Martinez $\mathrm{S}$. Concordance in diagnosis of diabetic retinopathy by fundus photography between retina specialists and a standardized reading center. Mexico City Diabetes Study Retinopathy Group. Arch Med Res 1995;26:127-31.

49. O'Hare JP, Hopper A, Madhaven C, et al. Adding retinal photography to screening for diabetic retinopathy: a prospective study in primary care. BMJ 1996;312:679-82.

50. Jacob J, Stead J, Sykes J, Taylor D, Tooke JE. A report on the use of technician ophthalmoscopy combined with the use of the Canon non-mydriatic camera in screening for diabetic retinopathy in the community. Diabetic Med 1995;12:419-25.

51. Ryder B. Screening for diabetic retinopathy [editorial]. BMJ 1995;311:207-8. 